\title{
7 \\ Surgery at the Children's Hospitals
}

Great Ormond Street and the other paediatric hospitals founded in the 1850s and 1860s were intended for the observation and nursing of sick children and not for the reception of accident cases, traditionally the responsibility of general hospitals, nor for much surgery of any kind but the very simplest. Limited size and funding required the most careful use of available beds and, since children needing operations were admitted to other hospitals, it seemed sensible to reserve the new accommodation for children with diseases not previously deemed suitable for inpatient care. Furthermore, at the time major surgery was frequently lethal due to the common incidence of ill understood post-operative sepsis, so the best way to avoid unpleasantly high mortality rates was to curtail operative procedures. Gradually this policy was changed, in part because the steady growth in size of most hospitals allowed for more liberal admissions but also because improved surgical techniques and attention to the prevention of sepsis were reducing post-operative morbidity and mortality. During the nineteenth century, however, most surgical innovation was undertaken in the general hospitals and then, if and when established as feasible, performed in the paediatric institutions. Greater risks could be taken in the established hospitals, with a long tradition of surgery, and they also had larger departments and the specialized nursing staff essential for successful intervention.

The regulations governing Great Ormond Street at its inception included the following proviso:

Children suffering from accidents or external injuries or their immediate effects are not in general eligible for admission as inpatients, the Hospital being intended for children suffering from diseases peculiar to, or modified in some important respect by, their early age. ${ }^{1}$

As indicated by Thomas Twistington Higgins, Charles West and some of his colleagues did not wish to appoint a surgeon to the staff of the hospital because in 'their opinion that there were no surgical problems in childhood which demanded special skill or study; that, therefore, no such appointment was required'. ${ }^{2}$ In the pre-anaesthetic era surgery for children had been more or less confined to the lancing of abscesses, the amputation of limbs and the removal of bladder stones, all conditions where a youngster would be treated much the same as an adult. Also, since children under the age of two years were to be excluded from admission to the paediatric hospitals, congenital disorders requiring surgery, such as imperforate anus, hare-lip and cleft palate, could be ignored. Chloroform, which was to be the standard anaesthetic agent in British hospitals, was introduced only in 1847 , so West may not have appreciated how extensively this new agent would enhance the practice of operative surgery. His attitude also reflected the age-old contention that

1 Thomas Twistington Higgins, 'Great Ormond Street', 1852-1952 (London: Odham's Press, 1952), p. 18.

2 Ibid., p. 20. 


\section{Surgery at the Children's Hospitals}

medicine was the more intellectually demanding and therefore superior branch of the profession.

Nevertheless, one surgeon was appointed at Great Ormond Street. Similarly, the Birmingham Children's Hospital, which opened in 1862, was also intended for medical cases but, as indicated by Rachel Waterhouse, here again it was found necessary to provide for the performance of minor operations. ${ }^{3}$ More simply, the Edinburgh Children's Hospital, founded in 1860 , made no provisions whatever for the admission of surgical cases which continued to be received and treated at the Edinburgh Royal Infirmary. ${ }^{4}$ The attending surgeons from the Infirmary kept pressing for surgical beds at the Children's Hospital but, as late as 1871 , the directors of the latter institution regretted their inability to establish a surgical ward and theatre because of lack of funds and space. ${ }^{5}$ Later, closure of the fever wards freed beds which were appropriated for surgery in 1887 . Nevertheless, most paediatric operations continued to be performed at the Infirmary until 1895, when the Edinburgh Children's Hospital was moved to a new, larger site. In contrast to all of the above, when a small paediatric hospital was established in Liverpool in 1859, the planning committee decided to exclude all fever cases and instead to admit surgical cases, mainly children suffering from chronic orthopaedic disabilities or what was then known as scrofula. ${ }^{6}$ Complicated surgery was not envisaged at Liverpool but rather the provision of good food and nursing, and complete rest as required by children with long-term diseases such as scrofula of the bones and joints.

At Great Ormond Street the provisional committee finally voted to appoint a surgeon and insisted that he should be well qualified, a fellow of the Royal College of Surgeons of England. For it very rapidly became obvious that, whatever the regulations about inpatients, and even with victims of accidents excluded, a large proportion of outpatients would be surgical cases. Although all the children attending were supposed to be recommended by subscribers to the hospital, many were brought by anxious parents or friends without any letters of introduction. Either way far more children with chronic surgical problems presented themselves than could be cared for and governors to the hospital were soon complaining that patients they had recommended were being turned away. So much so that in May 1857 the medical committee proposed the following clause be added to the annual report to explain the rejection of patients sent with subscribers' letters:

Many cases of rickets, of hip-joint disease or of scrofulous disease of the spine, or of the joints, are of necessity refused: either because they are quite incurable, or because they require nothing but rest for many months, or because good diet and fresh air for months or years are essential to improvement; and the reception of such cases would convert the hospital into an asylum for sickly children, instead of a place for the treatment and cure of the diseases of childhood.

${ }^{3}$ Rachel Waterhouse, Children in Hospital: A Hundred Years of Child Care in Birmingham (London: Hutchinson, 1962), p. 79, indicates that 'in 1864 five squints, three hernias, three club feet, six lithotomies, two tonsillectomies, one hare-lip, four operations on naevi, and seven tracheotomies were performed'.

4 Douglas Guthrie, The Royal Edinburgh Hospital for Sick Children 1860-1960 (Edinburgh: E. \& S. Livingstone, 1960), p. 19.

5 F. H. Robarts, 'The Origins of Pediatric Surgery', the James J. Mason Brown Memorial Lecture, R.C.S.Ed., 1 Nov. 1968, text at the Library of the Royal College of Surgeons of Edinburgh, no pagination.

6 Report by Dr. John Syer Bristowe and Mr. Timothy Holmes on the Hospitals of the United Kingdom, B.P.P., 1864, XXVIII, pp. 463-743 (482).

${ }^{7}$ Great Ormond Street Archives, Medical Committee Minute Book, Vol. I, p. 55, 27 May, 1857. 


\section{Elizabeth M. R. Lomax}

The above announcement would be repeated in each annual report. The aim was to mollify subscribers and governors while trying to avoid filling the hospital with chronic surgical cases, as would initially happen at Liverpool. To cope with at least some of the children requiring conservative care, the Alexandra Hospital for Children with Hip Disease was opened in 1867 . With only 10 cots at their disposal, the founders, Miss Catherine Wood and Miss Spencer Percival, intended to admit only children who had been discharged from Great Ormond Street, or who had failed to gain admission there. Excluded were patients with spinal disease and those who had undergone excision of the hip. ${ }^{8}$ By 1872 , the hospital had 50 beds but the above restrictions were maintained, providing some indication of the constant high demand for orthopaedic beds. The three small London orthopaedic hospitals, the National Orthopaedic, the Royal Orthopaedic, and City Orthopaedic, also cared for chronically sick children. Nor was this predominance of orthopaedic cases peculiar to London, or even to great Britain for, according to Clement A. Smith, the Children's Hospital of Boston, founded in 1869 , 'was primarily known as an orthopedic hospital' for the first fifty years of its existence. 9

In spite of constraints, by 1862, children with diseases of the bones and joints formed the largest single group (10.7 per cent) admitted as inpatients at Great Ormond Street. In so far as outpatients were concerned, by the same year, 'rickets' was the third commonest condition for which children were 'admitted' to the outpatient rolls (i.e. accepted as a regular outpatients to be seen more than once). 8.4 per cent of 'admitted' outpatients for 1862 suffered from rickets, whereas 2.6 per. cent had disease of the bones and joints and a further 2.3 per cent presented with abscesses and ulcers. To this undoubted collection of surgical problems may be added children suffering from scrofula and tuberculosis ( 2.4 per cent) or from syphilis ( 1.6 per cent), who were more likely to be seen by the surgeon than by the physician in attendance. This sizable proportion of surgical cases was not due to any obviously articulated change in hospital policy but seems to have reflected demand as expressed by the types of patients brought to the hospital dispensary. Although operative surgery was kept to a minimum at Great Ormond Street during the early years, more extensive and ambitious work was undertaken following the appointment in 1859 of Timothy Holmes, a young surgeon imbued with the new outlook on the expanding potential of operative intervention.

Surgery required dedicated practitioners for its development under the benefits of anaesthesia was beset by an apparently insuperable problem-the persistence of frequently lethal post-operative sepsis. Patients continued to die of inflammation of internal organs, tetanus, gangrene, suppuration, haemorrhage, and other forms of what was then considered as putrefaction or decomposition. Indeed, according to John Woodward, the incidence of pyaemia (envisaged as pus in the blood and evidenced at autopsy by abscesses scattered throughout the body) as a cause of death increased strikingly during the third quarter of the nineteenth century. ${ }^{10}$ Actually the term 'pyaemia'

\footnotetext{
${ }^{8}$ Annual Report of the Hospital for Hip Disease in Childhood (London, 1872), p. 4.

9 Clement A. Smith, The Children's Hospital of Boston (Boston: Little, Brown, 1983), p. 67.

10 John Woodward, To Do the Sick no Harm: A Study of the British Hospital System to 1875 (London: Routledge and Kegan Paul, 1974), pp. 110-11. Lindsay Granshaw, "Upon this Principle I have Based a Practice": The Development and Reception of Antisepsis in Britain, 1867-90', in John V. Pickstone (ed.), Medical Innovations in Historical Perspective (New York: St. Martin's Press, 1992), pp. 17-46, points out that although shock caused more deaths, it was hospital disease that 'came to be seen as intolerable in its incidence'. See also Sydney Selwyn, 'Hospital Infection: The First 2500 Years', Journal of Hospital Infection, 18 (1991, Supplement A): 5-64.
} 


\section{Surgery at the Children's Hospitals}

seems to have come into use only in 1857 , which supports the contention that a novel form of sepsis was making its appearance, although it could well have existed unrecognized in the pre-anaesthetic era since fewer major operations were then undertaken. Most certainly contemporary observers and practitioners believed hospital sepsis to be on the increase at mid-century. In all events, even if the rate of infection remained constant, a sizable increase in the number of operations performed entailed a rise in hospital death rates as surgical cases became proportionally more numerous.

Contemporary medical journals were replete with letters and articles debating the causes of hospital mortality. ${ }^{11}$ One group, headed by Florence Nightingale, Sir James Young Simpson, and William Farr, sought to establish a relationship between postoperative death rates and size of hospital. In their opinion, small provincial hospitals were inherently safer than large city hospitals whose construction and organization were therefore deficient. As is well known, Florence Nightingale ridiculed the existence of contagious diseases and ascribed 'infection' to poor ventilation, air poisoned by decomposed material including human exhalations, overcrowding, lack of cleanliness, and bad management. ${ }^{12}$ In her opinion, backed by statistics, the large city hospitals were death traps. Deriving her figures from William Farr's Appendix to the Report of the Registrar-General for 1861, Nightingale asserted that the twenty-four London hospitals had a mortality of 90.84 per cent, while twenty-five county hospitals had a death rate of 39.41 per cent per annum. These amazing figures were reached by comparing the total number of deaths per year in these hospitals with the bed occupancy at any one time. If a 300 bedded hospital had more than 300 deaths per annum then the mortality was over 100 per cent, irrespective of the total number of patients admitted during the year. When critics jibed at the methodology used, Farr came to Nightingale's defence. ${ }^{13}$ To placate the growing number of irate metropolitan surgeons, Farr indicated that not they but the hospitals were responsible for the deaths from pyaemia and erysipelas.

One unmollified practitioner was Timothy Holmes. Born in 1825, the son of a warehouseman, Holmes went to Merchant Taylors' School, then gained an exhibition to Pembroke College, Cambridge. He studied medicine at St. George's Hospital, and was awarded the F.R.C.S. in 1853 without previously taking the usual diploma of membership. He became a house surgeon, then surgical registrar, at St. George's Hospital. In 1859, he was appointed assistant surgeon at Great Ormond Street and promoted to full surgeon in 1861. An active man and a prolific writer, during the 1860 s he was editor of $A$ System of Surgery, Theoretical and Practical (1860-1864), together with Dr. John S. Bristowe he prepared a report on hospitals and their administration which was published as an appendix to the 6th annual report of the Public Health Department of the Privy Council (1863), and by 1868 he had published a Treatise on the Surgical Treatment of the Diseases of Infancy and Childhood, based on the experience gained at Great Ormond Street. The same year he resigned his post at the Hospital for Sick Children having been appointed full surgeon at St. George's Hospital.

\footnotetext{
11 An account of the debates may be found in Woodward, To Do the Sick no Harm, pp. 97-122.

12 For a discussion of her medical views see Charles E. Rosenberg, Explaining Epidemics and other Studies in the History of Medicine (Cambridge: University Press, 1992), pp. 90-108.

13 'Miss Nightingale's "Notes on Hospitals". Letter from Dr. Farr', Medical Times and Gazette, i (1864): 186-7; response by the editor of the Medical Times and Gazette, ibid., 187-8.
} 
In their 1863 report to the Privy Council, Bristowe and Holmes indicated that several factors affected the sanitary state of a hospital, including the severity or urgency of cases admitted. Later, in a letter to the Medical Times and Gazette, Bristowe demonstrated the absurdity of the Nightingale/Farr method of calculating hospital death rates. ${ }^{14}$ Nevertheless, no one found current post-operative mortality rates encouraging and controversy as to causes persisted. In the late $1860 \mathrm{~s}$, Holmes was once again defending the salubrity of metropolitan hospitals, this time in answer to Sir James Young Simpson, who had revived the proposition that rural institutions were safer than urban ones mainly because they were smaller and less crowded. ${ }^{15}$ Statistical returns on death rates after amputation supported Simpson's contention that survival was more likely in rural practice but his solution, to build hospitals as separate units, or 'villages', rather than as massive structures, was neither practical nor appealing to city dwellers and ratepayers. Least of all was it attractive to surgeons who had no desire to see their convenient bases of operation closed down and replaced by small, scattered institutions. So they argued that the cause of higher mortality in city hospitals was not intrinsic to institutional structure but due instead to types of patients treated. 'Is it not a reasonable and probable idea', asked Holmes, 'that the simpler and healthier habits of the rural population render them more capable of resisting the shock of injuries or operation? In the case of injury', he continued, 'may not the general run of injuries demanding amputation in the country be less hopeless than those seen in large towns'? ${ }^{16}$

Debate continued but the Nightingale-Farr-Simpson opinion that defective hospital sanitation rather than patient constitution was the root cause of sepsis generally prevailed in modified forms. In 1874, John Eric Erichsen, senior surgeon to University College Hospital, pointed out that among the London hospitals the percentage of post-operative deaths attributable to sepsis varied extensively even though there was little difference in health or status between patients treated. ${ }^{17}$ Yet he did not agree with Simpson's thesis that mortality from septic disease increased in direct proportion to the size of the hospital, since the largest metropolitan hospital-St. Bartholomew's-was currently reporting the lowest death rate from sepsis. In the opinion of Erichsen, acute pyaemia developed as 'the result of exposure of wounds to an atmosphere overcharged with organic matter emanating from other patients with suppurating wounds' ${ }^{18}$ Overcrowding of wards with patients suffering from septic lesions was therefore a critical factor in inducing 'hospitalism'.

Erichsen then discussed factors, other than the state of the wards, which might contribute to the high rate of mortality then associated with amputation of limbs. Having dismissed the skill of the operator and the constitution of the patient as more or less

\footnotetext{
14 J. S. Bristowe, 'Hospital mortality', Medical Times and Gazette, i (1864): 491-2.

15 For Sir James Y. Simpson's criticism of large hospitals see, 'Surgical and Maternity Hospitals', Medical Times and Gazette, i (1869): 72-3 ; 'Statistics of Operations in Private Country Practice', ibid., 280-1; Sir James Y. Simpson, 'Effects of Hospitalism on the Mortality of Limb-Amputations, etc.', British Medical Journal, i (1869): 93-4; Sir J. Y. Simpson, 'On the Relative Danger to Life from Limb-Amputations', ibid., 393-4; and 'Hospitalism: Its Influence upon Limb-Amputations in the London Hospitals', ibid., 533-5. For Holmes's rejoinders see, 'Hospital Mortality', British Medical Journal, i (1869): 87-8; and 'Hospitalism', ibid., 132-3.

${ }_{16}$ T. Holmes, 'Hospital mortality', British Medical Journal, i (1869): 87-8.

17 John Eric Erichsen, 'Hospitalism: and the Causes of Death after Operations', British Medical Journal, i (1874): 193-6.

18 Erichsen, 'Hospitalism', British Medical Journal, i (1874): 131-4.
} 


\title{
Surgery at the Children's Hospitals
}

constant in the large metropolitan hospitals, he focused on post-operative treatment. In over twenty-five years of practice he had tried various methods but the mortality rate among his patients had remained constant at 23 to 25 per cent. Early on, when working under Liston, he had left the amputation flaps open, with the wound exposed to the air, until all oozing had ceased. The wound was then closed and water dressings applied. Later Erichsen decided to close the wound immediately after amputation and to wash the stump with a variety of disinfectants. Some of his patients had been subjected to the full antiseptic treatment, more or less as recommended by Lister, but not yet in sufficient number for Erichsen to come to any conclusion as to the method's practical merits.

\begin{abstract}
The essential point in the local treatment of any wound being scrupulous attention to cleanliness, the absolute purity, so far as freedom from all decomposable organic matter is concerned, in everything that is brought into contact with it, be it air, or instruments, or dressings, or surgeon's fingers, and close personal supervision. In all these respects, the "antiseptic treatment" of Lister, and Callender's method of managing stumps, leave nothing to be desired; and, if I were to venture an opinion upon a subject which is still sub judice, I should say that it is in this that their great merit in practice consists. But we have, as yet, to learn the real value of antiseptic methods of treatment; and this can only be done by the observation of a very extended series of cases in which these plans of treatment have been employed and comparing the results thus obtained with an equally extensive set of cases treated by other methods under as nearly as possible the same conditions in the same hospital. ${ }^{19}$
\end{abstract}

Although a believer in miasma rather than germs as the cause of wound infection, Erichsen was prepared to accept the carbolic method of dressing if it could be demonstrated as superior to any other. However, as Nicholas Fox, Lindsay Granshaw, Christopher Lawrence and Richard Dixey have indicated, most of the alternatives to Listerism developed by the 1870 s were more acceptable to British surgeons because they were simpler to apply, did not involve the constant use in the operating theatre of the cumbersome carbolic spray and, perhaps most importantly, depended on the acceptance of miasma rather than air born germs as the cause of wound infection. ${ }^{20}$ 'Scrupulous attention to cleanliness', to borrow Erichsen's insight, was the critical factor in these alternative methods. The above historians further insist that these methods, rather than Lister's antiseptic technique, were the forerunners of aseptic surgery later in the nineteenth century because of the shared insistence on absolute cleanliness not only of the wound and the surgeon's hands and instruments but also of the whole environment in the operating theatre and wards. Lister was originally unperturbed by extraneous dirt. He relied on carbolic dressings and the spray to destroy the germs that could cause putrefaction of the wound and was quite laggard in accepting the ritual of asepsis which he thought unnecessary if the antiseptic method was properly applied.

19 Ibid., 193-6.

${ }^{20}$ Nicholas J. Fox, 'Scientific Theory, Choice and Social Structure: The Case of Joseph Lister's Antisepsis, Humoral theory and Asepsis', History of Science, 26 (1988): 367-97; Lindsay Granshaw, "'Upon this Principle I have Based a Practice"', in Pickstone (ed.), Medical Innovations in Historical Perspective; Christopher Lawrence and Richard Dixey, 'Practising on Principle: Joseph Lister and the Germ Theories of Disease', in Christopher Lawrence (ed.), Medical Theory, Surgical Practice: Studies in the History of Surgery (London: Routledge, 1992), pp. 153-215. 
In the 1860 s and early 1870 s, when so many paediatric hospitals were instituted, the debates on hospital infection were mainly conducted on miasmic principles, involved all aspects of institutional care, medical, surgical and outpatient, and were often based on an uneasy feeling that once a building was thoroughly infected it was unreclaimable. The governors of the Manchester Children's Hospital were so convinced of the inevitability of atmospheric pollution at Bridge Street that they arranged for a new hospital to be built at Pendlebury, a rural area about four miles from the city centre. Opened in 1872, and initially costing the then impressive sum of $£ 23,000$, Pendlebury Hospital was built on the pavilion plan recommended by Florence Nightingale. ${ }^{21}$ Special ambulances and a private telegraph service were instituted to ensure speedy communication with the outpatient department which remained at Gartside Street, Manchester. Other children's hospitals also took measures to reduce pollution varying from improving toilet and washing facilities to abandoning their original sites and relocating in new or improved buildings, with the need for expansion as an added justification for the expense involved. Yearly sanitary inspections of institutions, paid for by the hospitals themselves, also became the rule.

While the children's hospitals were prepared to police themselves, investigation from outsiders was discouraged. In 1871, Lawson Tait sent a circular to over 300 hospitals requesting information as to the number of beds, the number of inpatients and the number of deaths for the decade 1861 to $1870 .{ }^{22}$ In 1876 he again applied for the same statistics for the years 1870-1875. Apart from the Birmingham Children's Hospital, which was forthcoming on both occasions, the returns from the paediatric hospitals were disappointing to Tait. Great Ormond Street sent reports he found defective, the majority of paediatric hospitals merely replied to the first request, and the two Manchester hospitals ignored both. Since, in 1871, the Manchester Children's Hospital was about to move to Pendlebury, its governors may have felt that any previous statistics were irrelevant. But overall one gets the impression that the managers of the children's hospitals were avoiding the dissemination of information that might serve as adverse publicity for their still fragile institutions. Lawson Tait used the statistics gathered as the basis of his Essay on Hospital Mortality, published in 1877.

With respect to surgical mortality, antisepsis, scrupulous cleanliness and finally asepsis had their impact. Associated in time with these changes in surgical practice was reform in nursing, leading to the staffing of surgical wards with women trained to understand and carry out the imperatives of asepsis. ${ }^{23}$ As death rates from infection declined, more ambitious operations were performed not simply to save life or to rectify completely disabling deformities, but now also for less pressing reasons. For example, in the preantiseptic era bandaging or splints were used to correct the often severe leg deformities caused by rickets, a very common disease in the nineteenth century. In 1852, Dr. Meyer of

${ }^{21}$ Forty-Fourth Annual Report of the General Hospital and Dispensary for Sick Children (Manchester: 1873), p. 6.

22 Lawson Tait, An Essay on Hospital Mortality: based upon the Statistics of the Hospitals of Great Britain for Fifteen Years (London: J. \& A. Churchill, 1877), p. 9.

23 This association was pointed out to me by Christopher Lawrence, who notes that many of Lister's contemporaries believed that the increasing success of wound management was not due to any revolutionary method of treatment, but to 'the banishment of fevers from the wards which, in turn, ... derived from general sanitary, dietary, nursing, and architectural reform', Lawrence and Dixey, 'Practising on principle: Joseph Lister and the germ theories of disease', in Lawrence (ed.), Medical Theory, Surgical Practice, p. 157. 


\section{Surgery at the Children's Hospitals}

Würtzburg introduced the operation of osteotomy (entailing partially dividing the shaft of femur or more commonly the tibia, straightening the limb, and then treating it like an ordinary compound fracture) to deal with severely distorted, refractory cases. Because of the risk of sepsis, osteotomy was rarely performed until the mid-1870s. From then on, however, it became an accepted manner of correcting deformity in older children whose bones were no longer sufficiently plastic to be straightened by splinting. ${ }^{24}$

Holmes's 1868 textbook and his Great Ormond Street case notes for the years 1861 to 1867 provide valuable insights into paediatric surgical practice in the pre-Listerian era (see Table 11). The majority of his inpatients were suffering from necrosis or sepsis of the bones and joints. Of these a large number were almost certainly of tuberculous origin but not necessarily so recognized at the time. Holmes himself, like most surgeons, subscribed to a diagnosis of struma, or scrofula, sometimes defined 'as being the constitutional diathesis which leads to, or which at the least tends to favour, the deposition of tubercle' ${ }^{25}$ On deeper analysis, however, Holmes found this definition objectionable because it was too definite, too unyielding. Since, in his experience, many cases of scrofula made a good recovery without any evidence of becoming tuberculous, it seemed more practical to consider the 'scrofular diathesis' as separate from the 'tubercular' one.

At the time scrofula and tuberculosis were commonly regarded as independent constitutional or 'diathetic' diseases. ${ }^{26}$ What was inherited, according to this theory which had its roots in Hippocratic medicine, was the liability to acquire tuberculosis or scrofula given the appropriate environmental trigger. The predisposition was hereditary not the disease itself. The 'tubercular diathesis' was thought to be commonest in active children, with a highly developed nervous system, clear complexion, bright eyes, and slight build, representing the 'sanguine' or 'nervous' disposition. In contrast, a 'scrofular diathesis' might be suspected in dull, heavy, lethargic children, with a muddy complexion, coarse skin, and other signs of a 'phlegmatic' constitution. ${ }^{27}$ The humoral origins of such typing are too obvious to belabour, and even French physicians such as Jean Guillaume Lugol, Frédéric Rilliet and Antoine Barthez, who believed tuberculosis and scrofula to be identical diseases, held to a constitutional origin. ${ }^{28}$ In France the unified theory did make headway, but German and British physicians were more sceptical, in part, ironically enough, because of their greater reliance on the new science of microscopy to determine pathology. This line of investigation added to the confusion by multiplying perceived variations in cell types and forms to be found in scrofular and consumptive lesions:

\footnotetext{
${ }^{24}$ Howard Marsh, 'On the Treatment of Rickety Deformities of the Legs by Operation', British Medical Journal, i (1874): 274-5 (Marsh applied antiseptics to the wounds post-operatively but apparently did not use the carbolic spray during surgery); Thomas Annandale, 'On a New Operation for the Cure of Certain Cases of Aggravated “Knock-Knee”, Edinburgh Medical Journal, 21 (1876): 18-20; Alexander Ogston, 'The Operative Treatment of Genu Valgum', Edinburgh Medical Journal, 22 (1877): 782-4; William Macewen, 'Antiseptic Osteotomy for Genu Valgum, Genu Varum, and other Osseous Deformities', Lancet, ii (1878): 911-14.

${ }_{25}$ Timothy Holmes, Surgical Treatment of the Diseases of Infancy and Childhood (London: Longmans, Green, Reader and Dyer, 1868), p. 334.

${ }^{26}$ For an analysis of seventeenth- and eighteenth-century perceptions of scrofula, see: Roger French, 'Surgery and Scrophula', in Lawrence (ed.), Medical Theory, Surgical Practice, pp. 85-100.

27 The distinctions between the tuberculous and scrofulous types of constitution may be found in, for example, Eustace Smith, On the Wasting Diseases of Infants and Children (London: J. \& A. Churchill, 1878), pp. 237-9; and 'Remarks on the Tuberculous and Strumous Diatheses, by Dr. Wilkes', Lancet, ii (1873): 807-8.

28 J. G. Lugol, Researches on Scrofulous Diseases, trans. A. Sidney Doane (New York, 1847); A. C. E. Barthez and F. Rilliet, Traité clinique et pratique des maladies des enfants, 3 vols (Paris: Germer-Baillière, 1853-54).
} 


\section{Elizabeth M. R. Lomax}

'... there yet are differences between tuberculosis and scrofula at least as marked as those which separate diphtheria from scarlatina', wrote Charles West in 1865, 'and the tendency of pathological research appears to be to render these differences more and more obvious. ${ }^{29}$ Whereas naked eye examination of tubercular and scrofular lesions, and consideration of how often the maladies coexisted, had induced a few French physicians to perceive the overwhelming importance of similarities, new complexities with the introduction of microscopy once more muddied the field.

Nevertheless, by mid-century much more was known about the pathology of scrofula and phthisis. The latter condition was recognized as due to the presence of tubercles in the lungs. It was also accepted that not only adults but also children and babies were liable to pulmonary tuberculosis with the proviso that in the very young tubercles were rarely confined to the lungs but were often disseminated in other organs including the meninges. Thus many previously mysterious ailments of infancy, such as acute hydrocephalus, were established as being of tubercular origin and the term 'tuberculosis' used to designate them all. Difficulties arose with the scrofular affections because they were sometimes, even frequently, but not always, associated with the formation of tubercles. For many French physicians the evidence was sufficient to establish unity. Frédéric Rilliet and Antoine Barthez discussed all forms under the category of diathèse scrofulo-tuberculose in their influential Traité clinique et pratique des maladies des enfants (1854). But in Britain the more conservative tendency to retain two separate diatheses held sway. In the 1860 s, both West and Holmes wrote about the two conditions as distinct. ${ }^{30}$

Most of Holmes' patients were seriously ill and in, his opinion, beyond the stage when rest, good food and good nursing might have affected a cure. In the more fortunate, infection had localised to form an abscess which could be opened and drained. Frequently, underlying necrosed cartilage or bone required scraping out, but if most of the dead material was removed, and further infection did not supervene after surgery, the child had some chance of recovering with a serviceable limb. In more advanced disease, the choice was between resection of a joint and amputation. When the primary illness was osteomyelitis, or inflammation of the bone, chronic disease entailed the gradual dying off of bony tissue and, if this could not be removed in time, amputation of the limb was the only solution. If the joint was the primary site of infection, as so often occurred with 'scrofula' or tuberculosis, then some surgeons, including Holmes, would consider the possibility of removing the joint in preference to amputation. After resection of a joint, for example the knee, splints would be applied so that the raw ends of the tibia and femur were in apposition and, if all went well, bony fusion would gradually ensue. This would take months, even years, and the child would be left with an ugly, stiff, shortened, but serviceable limb. Unfortunately, much could go wrong. Fusion would not occur if complete immobility could not be maintained, as happened all too often with knee joints, and infection was commonplace. Then amputation, a quicker and safer operation in the first instance, would be the only remaining option. Although the more conservative

\footnotetext{
${ }^{29}$ Charles West, Lectures on the Diseases of Infancy and Childhood (Philadelphia: Henry C. Lea, 1866, from the 1865 English ed.), p. 583.

30 Charles West, Lectures on the Diseases of Infancy and Childhood (1866), pp. 583-8, for his description of scrofula, which he states to be 'closely allied in its essential nature to tuberculosis', but 'not identical'. Holmes, Surgical Treatment, pp. 334-41, made his distinctions in this section on 'struma', an alternative designation for scrofula.
} 


\section{Surgery at the Children's Hospitals}

operation of resection had been sporadically performed since the beginning of the century, in Britain it did not attract serious attention from surgeons until the mid-nineteenth century.

According to Holmes, chronic disease of the hip, or 'morbus coxarius' was even commoner than knee joint disease, although quite rare among children from wealthy families and those living in rural areas. ${ }^{31}$ If pain and swelling did not subside with bed rest, he usually recommended extension of the leg together with traction on the hip joint. If the disease progressed to abscess formation, drainage was instituted. But if the child continued to get sicker with unmistakable disintegration of the joint then Holmes would consider resection, on the principle that otherwise death was almost certain. He also pointed out that rarely could the families of patients attending voluntary hospitals cope with a bedridden child for the years necessary to ensure recovery from tuberculosis of the hip without surgery.

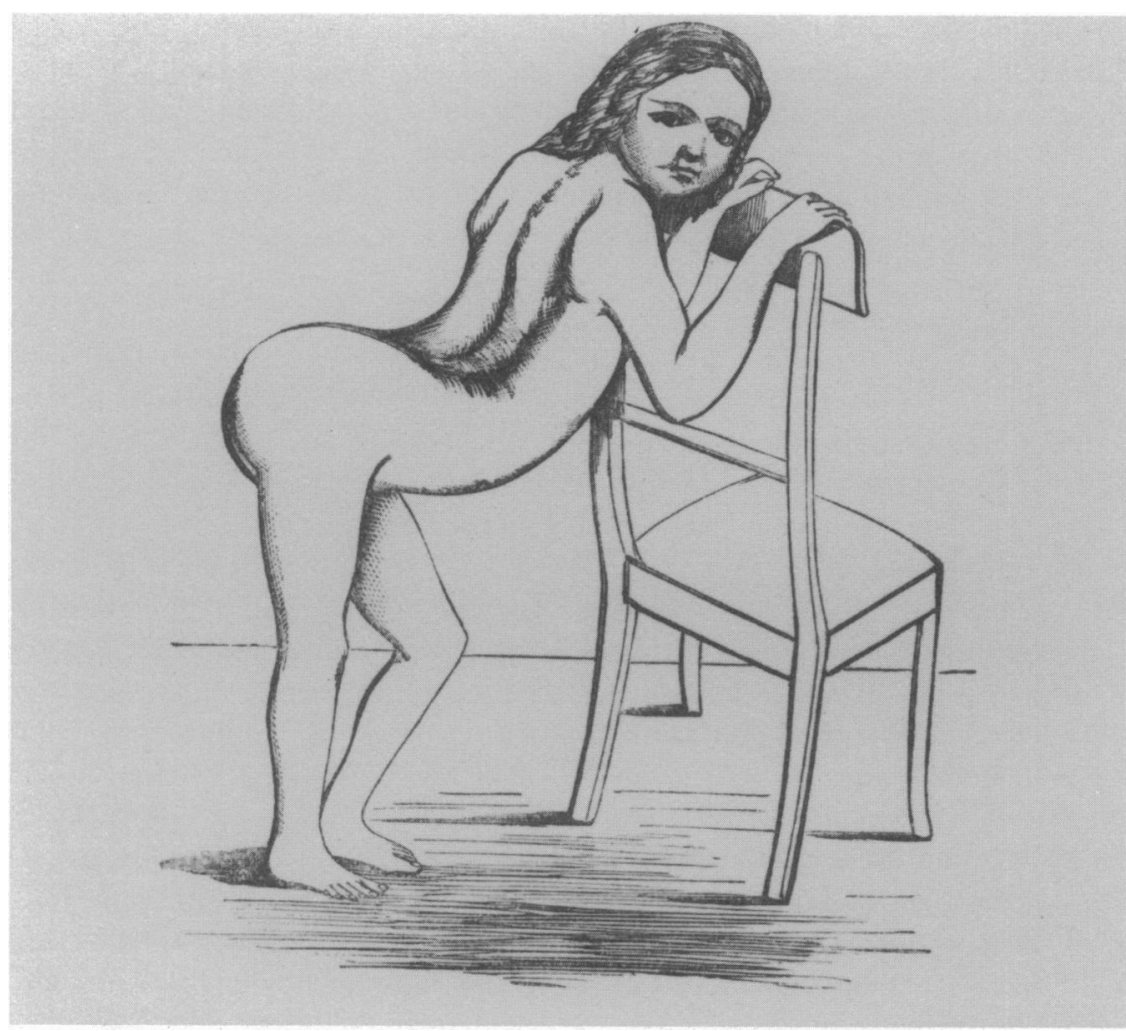

Figure 7: Illustration of deformity following the spontaneous cure of disease of the hip joint. (From Timothy Holmes, Surgical Treatment of the Diseases of Children, 1869, p. 440, fig. 72.)

${ }^{31}$ Holmes, Surgical Treatment, p. 434. Holmes also extensively discussed the excision of bones and joints in T. Holmes (ed.), A System of Surgery Theoretical and Practical in Treatises by Various Authors (London: Longmans, Green, 1871, 2nd ed.) pp. 654-727. 
In many cases I have known as much as six or seven years to elapse before recovery is complete, when the disease passes through all its stages, terminating in abscess. But during the whole of this time constant care and nursing are necessary, the limb should be carefully dressed and protected from all injury, and the health should be supported by fresh air, good diet, tonic medicines, etc. Now what chance have the children of the poor of getting all these things? Common sense must reply that they have none, and experience shows that spontaneous cure is not attained in their case. ${ }^{32}$

Holmes himself believed, in 1868 , that he had practised the operation of hip excision on children more extensively than any other surgeon. While at Great Ormond Street he had performed more than 20 such operations, for 19 of which the records are preserved (see Table 11). Seven of the 19 children died, one almost immediately after the operation, one of gangrene of the wound, and the other five of pyaemia. Three more recovered from the operation, only to die later, one from an independent illness and the others from the original disease. Of the nine long-term survivors, three recovered completely, three had useful limbs but with chronic sinuses, and three were hardly benefited, if at all. The operation entailed opening the joint and sawing off the head of the femur at the level of the greater trochanter. At the pelvic end, the acetabulum was cleaned and scraped. While the child was still under anaesthesia, the limb was placed in an extended position and held there with a weight and pulley. The usual result, according to Holmes, would not be bony union which was undesirable, but instead the stump of the femur would be drawn into the acetabulum, and held there, by the common tendon of the psoas and iliacus muscles. If successful, the leg would be shortened but the child could walk. Years of reasonable activity could be anticipated although presumably arthritis would set in later in life. Yet, given the high postoperative death rates, both long and short term, and the many children that remained invalids, some of Holmes contemporaries considered resection of the hip joint unjustified. Surgeons who favoured the operation argued that the high fatality rate was due to surgery usually being performed when the child was in extremis, and that excision of the hip should be undertaken sooner, 'as soon as caries of the joint had been diagnosed with certainty'. ${ }^{33}$

With the introduction of antiseptic methods excision of the hip became safer and more popular. As early as 1875, Thomas Annandale, surgeon to the Royal Edinburgh Infirmary, reported on 22 cases of excision of the hip of which 6 were young persons seventeen years of age or older, while 16 were children aged five to sixteen years. ${ }^{34}$ None died from the immediate effects of the operation, but two of the young adults and three of the children died several months after surgery from local and 'visceral' complications. Annandale thought that these favourable results, the best thus far reported by any British surgeon, were due to the consistent employment of Listerian antisepsis and to the performance of surgery at an early stage of disease.

Not all surgeons were persuaded. In 1877, Howard Marsh, assistant surgeon at Great Ormond Street, stated that he had little experience of hip resection and was unimpressed by the results he had witnessed. ${ }^{35}$ But, as mentioned in the introduction, the most

32 Holmes, Surgical Treatment, p. 458.

33 Thomas Annandale, 'On the Pathology and Operative Treatment of "Hip" Disease', Edinburgh Medical Journal, 21 (1875-76): 487-95.

34 Ibid., 487-495, and 694-699.

35 Howard Marsh, 'Lectures on the Diagnosis and Treatment of Hip-Disease in Children; Lecture IV', British Medical Journal, ii (1877): 129-31. 


\section{Surgery at the Children's Hospitals}

persistent opponent of major surgery for disease of the hip was Hugh Owen Thomas of Liverpool. In his text Diseases of the Hip, Knee and Ankle Joints, .. . Treated by a New and Efficient Method, first published in 1875, Thomas indicated, with a minimum of tact, not only that surgery was counterproductive but also that prevailing methods of resting the hip joint were useless. ${ }^{36}$ What he advocated and described was his own invention, to become renowned as the 'Thomas hip splint'. Whereas other models intended to immobilize the hip joint had been secured to the pelvis, the Thomas splint was attached to the chest, and so presumably was more effective. In addition it was relatively simple and cheap, and could be used not only at rest but also, with slight modifications, on an ambulatory patient.

Some of Thomas' biographers have tended to depict him as an orthopaedist whose brilliance was ignored by the medical profession until after his death, when his ideas and techniques were brought into hospital practice by his nephew Robert Jones. Yet Thomas' 1875 text was reviewed, albeit somewhat unfavourably, in the medical journals, his splints (including other models for the knee and ankle) were swiftly tried out in some London hospitals, and soon were in current use, as judged by references in contemporary medical texts. ${ }^{37}$ In 1887, Thomas gave an invited lecture to the Harveian Society of London on 'The Physical Signs of Disease of the Hip Joint, with a Demonstration of the Mechanical Fixation of the Joint' ${ }^{38}$ He never held a hospital appointment but this may have been by his own choice, or because he was perceived as too belligerent to fit into the institutional culture. As stated by one of his more impartial biographers, 'He had a way of promulgating his teachings and even of treating his patients that aroused opposition, not only among his competitors and critics, but even among his friends' ${ }^{39}$

Excision of the hip joint was most frequently performed during the 1880 s, and thereafter became less popular, as did resections of other joints and amputations of limbs. In part this more conservative approach was due to the increased number of surgical beds available, allowing a certain number to be used for longer term care. Also improved survival rates meant that repeated surgery was now far more justifiable. The most conservative operation could be undertaken first and, if this measure failed, further more complex intervention carried out. Thus, instead of turning to immediate amputation, or the excision of joints, late-nineteenth-century surgeons more commonly advocated long term rest and splinting of the diseased limb as a first measure. If surgery became necessary the least mutilating operation could be undertaken first. As may be seen from the table of major operations at Pendlebury, 27 excisions of the hip were undertaken in 1881, but only 3 in 1900 (see Table 13). On the other hand, 66 patients underwent 'exploration of the hip' in 1900 , whereas twenty years earlier only 4 children had their probably tubercular joint treated thus conservatively. By the 1890 s, erasion (cutting out all the diseased tissue) was

\footnotetext{
${ }^{36}$ Hugh Owen Thomas, Diseases of the Hip, Knee, and Ankle Joints, with their Deformities, Treated by a New and Efficient Method (Liverpool, 1876; facsimile reprint Boston: Little, Brown, 1962).

37 'Thomas's Splint was being fairly tried on the wards' of the London Hospital, according to the British Medical Journal, ii (1876): 113, and of University College Hospital, ibid., 147. In his 1877 'Lectures on the Diagnosis of Hip-Disease in Children', given at Great Ormond Street, Howard Marsh described and recommended the Thomas splint, ibid., ii (1877): 129.

38 Ibid., i (1887): 1100.

39 H. Winnet Orr, On the Contributions of Hugh Owen Thomas of Liverpool, Sir Robert Jones . . John Ridlon ... to Modern Orthopedic Surgery (Springfield, Illinois: Charles C. Thomas, 1949), p. 26.
} 
'practically the only operation done at the [Manchester] children's Hospital for tubercular disease of the knee. Excision and amputation are almost unknown there for this joint' ${ }^{40}$ The chart for Great Ormond Street does not so clearly indicate the change in tactics but it will be noted that although 11 excisions of the hip joint were performed in 1893, none of these operations were undertaken in 1899 (see Table 12). Instead, the same year, no less than 45 children had their abscesses of the hip joint cleaned by incision and scraping, the equivalent of 'exploration of the hip'. Probably to no one's regret, heroic surgery for tubercular joints was fast becoming unnecessary.

40 Henry Ashby and G. A. Wright, The Diseases of Children, Medical and Surgical (London: Longmans, Green, 1899), p. 677. 